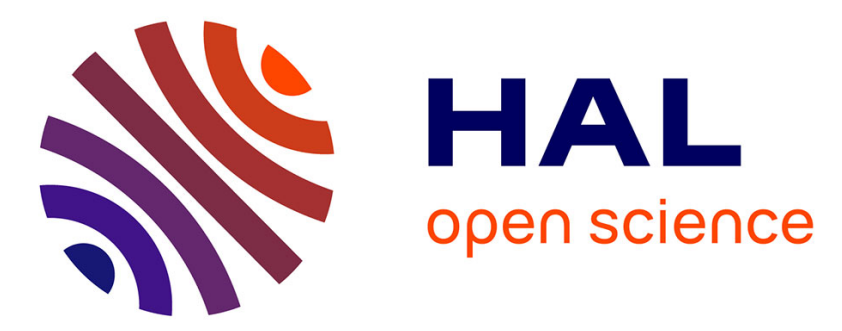

\title{
Towards robust and predictive geodynamic modelling: the way forward in frictional plasticity
}

Thibault Duretz, René de Borst, Philippe Yamato, Laetitia Le Pourhiet

\section{To cite this version:}

Thibault Duretz, René de Borst, Philippe Yamato, Laetitia Le Pourhiet. Towards robust and predictive geodynamic modelling: the way forward in frictional plasticity. Geophysical Research Letters, 2020, 47 (5), pp.e2019GL086027. 10.1029/2019GL086027 . insu-02498077

\section{HAL Id: insu-02498077 https://hal-insu.archives-ouvertes.fr/insu-02498077}

Submitted on 12 Mar 2020

HAL is a multi-disciplinary open access archive for the deposit and dissemination of scientific research documents, whether they are published or not. The documents may come from teaching and research institutions in France or abroad, or from public or private research centers.
L'archive ouverte pluridisciplinaire $\mathbf{H A L}$, est destinée au dépôt et à la diffusion de documents scientifiques de niveau recherche, publiés ou non, émanant des établissements d'enseignement et de recherche français ou étrangers, des laboratoires publics ou privés. 


\section{Geophysical Research Letters}

\section{RESEARCH LETTER \\ 10.1029/2019GL086027}

Key Points:

- Visco-elasto-viscoplasticity allows for robust modeling of crustal-scale shear banding

- Simulations satisfy equilibrium, and results converge to a physically realistic solution upon mesh refinement

- Models are verified using basic analytical relations and validated using laboratory rheological data

Supporting Information:

- Supporting Information S1

- Text S1

- Figure S1

- Figure S2

- Figure S3

Correspondence to:

T. Duretz,

thibault.duretz@univ-rennes1.fr

Citation:

Duretz, T., de Borst, R., Yamato, P., \& LePourhiet, L. (2020). Toward robust and predictive geodynamic modeling: The way forward in frictional plasticity. Geophysical Research Letters, 47, e2019GL086027. https://doi.org/10.1029/2019GL086027

Received 2 NOV 2019

Accepted 20 FEB 2020

Accepted article online 25 FEB 2020

(C)2020. American Geophysical Union. All Rights Reserved.

\section{Toward Robust and Predictive Geodynamic Modeling: The Way Forward in Frictional Plasticity}

\author{
Thibault Duretz ${ }^{1,2}(\mathbb{D})$, René de Borst ${ }^{3}(\mathbb{D})$, Philippe Yamato ${ }^{1,4}(\mathbb{D})$, and Laetitia Le Pourhiet ${ }^{5}$ (i) \\ ${ }^{1}$ Univ Rennes, CNRS, Géosciences Rennes UMR 6118, Rennes, France, ${ }^{2}$ Institut des Sciences de la Terre, University of \\ Lausanne, Lausanne, Switzerland, ${ }^{3}$ Department of Civil and Structural Engineering, University of Sheffield, Sheffield, \\ UK, ${ }^{4}$ Institut Universitaire de France (IUF), Paris, France, ${ }^{5}$ Sorbonne Universités, UPMC Univ Paris 06, CNRS, Institut \\ des Sciences de la Terre de Paris (iSTeP), Paris, France
}

\section{Introduction}

Lithospheric-scale strain localization is a crucial phenomenon that enables the occurrence of plate tectonics (Tackley, 2000; Ulvrova et al., 2019). The emergence of faults allows for the nucleation of plate boundaries and the specific shapes of tectonic plates, which subsequently can accommodate relative motions. While lithospheric deformations mainly take place in the ductile regime, where processes such as shear heating or grain size reduction control the emergence of strain localization (Bercovici et al., 2001; Kiss et al., 2019), crucial contributions to the deformation of the lithosphere as a whole occur in the frictional plastic-or brittle-regime. Indeed, in the colder regions of the lithosphere, that is, at shallow crustal levels and potentially at the top of the mantle lithosphere, frictional plasticity is the governing mechanism. As a result, the overall deformation is characterized by faulting and by the development of typical structural features such as tilted blocks, tectonic nappes, and fault zones.

It is known from laboratory experiments that the strength of rocks in the plastic domain exhibits a strong pressure dependence accompanied by a weak rate dependence (Byerlee, 1978; Rutter \& Glover, 2012). This observation has led to the development of frictional plasticity models, in which the shear strength is related to the normal stress via the angle of internal friction and the cohesion. Another peculiarity of the deformation of rocks is that plastic flow is virtually incompressible, definitely at high confining pressures. Thus, the difference between the internal friction $(\phi)$ and dilation $(\psi)$ angles is large, which is a typical feature of nonassociated plastic flow (Vermeer \& de Borst, 1984). Under such conditions, theoretical derivations (Anderson, 1905; Arthur et al., 1977; Vermeer, 1990) predict that faults occur at characteristic angles with the principal stress direction, which was confirmed by early analog models (Hubbert, 1937; McClay, 1990), as well as geological observations (e.g., Anderson, 1951; Brun et al., 1992; Coward et al., 1991; McLeod et al., 2000; Ori, 1989).

In the past decades, numerical modeling has become pivotal for studying geodynamic processes. Numerical models can analyze several physical phenomena simultaneously, for example, thermo-mechanical or hydro-mechanical problems, while handling complex rheological models, ranging from the brittle to the ductile regime. To this end, visco-elasto-plastic models (V-E-P) and visco-plastic models (V-P) have been employed widely (e.g., Fullsack, 1995; Gerbault et al., 1998; Poliakov et al., 1993; Willett, 1992). Such models 
rely on a series (Maxwell-type) arrangement of the rheological elements and assume the plastic deformation to be rate independent. This approach is successful at capturing the characteristic angles of shear bands formation (Kaus, 2010; Lemiale et al., 2008; Moresi et al., 2007). However, it is known that it is extremely difficult, if not impossible, to reach a converged equilibrium state using these models (Fraters et al., 2019; Spiegelman et al., 2016), which casts doubts on their reliability. Moreover, nonassociated flow or strain softening in the plasticity model induces a severe mesh sensitivity (de Borst et al., 1993), which adds to the questions regarding the reliability of geodynamic models to properly predict faulting. The behavior of rate-independent plastic flow contrasts with that of power law viscous flow, which generally leads to globally convergent and thus reliable numerical solutions (Adamuszek et al., 2016; Räss et al., 2017).

In the following, we apply an alternative rheological model, namely, a visco-elasto-viscoplastic model (V-E-VP), to study the evolution of shear bands in geodynamic models. We present two-dimensional models of crustal stress buildup in either extension or compression. It will be demonstrated that, besides a smooth convergence toward an equilibrium state is obtained within a tight tolerance, shear band patterns also converge upon mesh refinement, while preserving characteristic shear band angles. We compare our results to those obtained with a widely used V-E-P formulation and show clear improvements. Finally, we verify our results using fundamental analytical relationships and validate them by comparing numerically obtained stress states with classical laboratory data.

\section{Method and Model Configuration}

We consider a rheological model that puts in series a viscous dashpot, an elastic spring, and a viscoplastic element (Figure 1):

$$
\dot{\boldsymbol{\epsilon}}=\dot{\boldsymbol{\epsilon}}^{\mathrm{v}}+\dot{\boldsymbol{\epsilon}}^{\mathrm{e}}+\dot{\boldsymbol{\epsilon}}^{\mathrm{vp}},
$$

where the superscripts $v, e$, and $v p$ denote the viscous, the elastic, and the viscoplastic contributions, respectively. The viscous element (Figure 1a, left) relates the deviatoric effective stress, $\tau_{\mathrm{II}}=\sqrt{\frac{1}{2} \tau: \tau}$, to the deviatoric strain rate, $\dot{\varepsilon}_{\mathrm{II}}=\sqrt{\frac{1}{2} \dot{\boldsymbol{\epsilon}}: \dot{\boldsymbol{\epsilon}}}$. The viscous strain rate is governed by a temperature-activated power law creep relation, with the effective viscous strain rate defined as

$$
\dot{\varepsilon}_{\mathrm{II}}^{\mathrm{v}}=A \exp \left(-\frac{Q}{R T}\right)\left(\frac{\tau_{\mathrm{II}}}{2}\right)^{n}
$$

where $A$ is a coefficient, $n$ is an exponent, $T$ is the absolute temperature, $Q$ is the activation energy, and $R$ is the gas constant. The elastic element (Figure 1a, center) linearly relates stress to strain, and the effective deviatoric elastic strain rate reads

$$
\dot{\varepsilon}_{\mathrm{II}}^{\mathrm{e}}=\frac{\dot{\tau}_{\mathrm{II}}}{2 G}
$$

where $G$ is the shear modulus. The viscoplastic element (Figure 1a, right panel) includes a dependence on the pressure $P$ and on the effective viscoplastic strain rate, $\dot{\varepsilon}_{\mathrm{II}}^{\mathrm{vp}}$. Herein, we use the viscoplastic consistency model (Heeres et al., 2002; Wang et al., 1997), so that the yield function is expressed as

$$
F=\tau_{\mathrm{II}}-C \cos (\phi)-P \sin (\phi)-\eta^{\mathrm{vp}} \dot{\varepsilon}_{\mathrm{II}}^{\mathrm{vp}}
$$

with $C$ the cohesion, $\phi$ the angle of internal friction, and $\eta^{\mathrm{vp}}$ the viscosity of the damper. Different from previous studies (Duretz, Souche, et al., 2018; Duretz et al., 2019), plastic flow is assumed to be incompressible, so that the plastic strain rate is derived from a plastic potential, $Q=\tau_{\mathrm{II}}$. We employ a velocity-pressure formulation coupled to an effective viscosity rheological implementation (Moresi et al., 2003). These choices are deliberate in order to conform at most with classical implementations used in geodynamics (visco-elastic-plastic rheology and Picard linearization). We note that neither $C$ nor $\phi$ depend on the plastic strain history, so that strain weakening is not included in the present calculations. The methodology is described in Text S1 in the supporting information.

The resulting rheology is termed a visco-elastic-viscoplastic (V-E-VP) model (de Borst \& Duretz, 2020). It is different from the widely used visco-elastic-plastic (V-E-P) model, which also obeys equation (1) but merely has a plastic slider in the plastic element, making the plastic strain rate insensitive to the rate of deformation. 

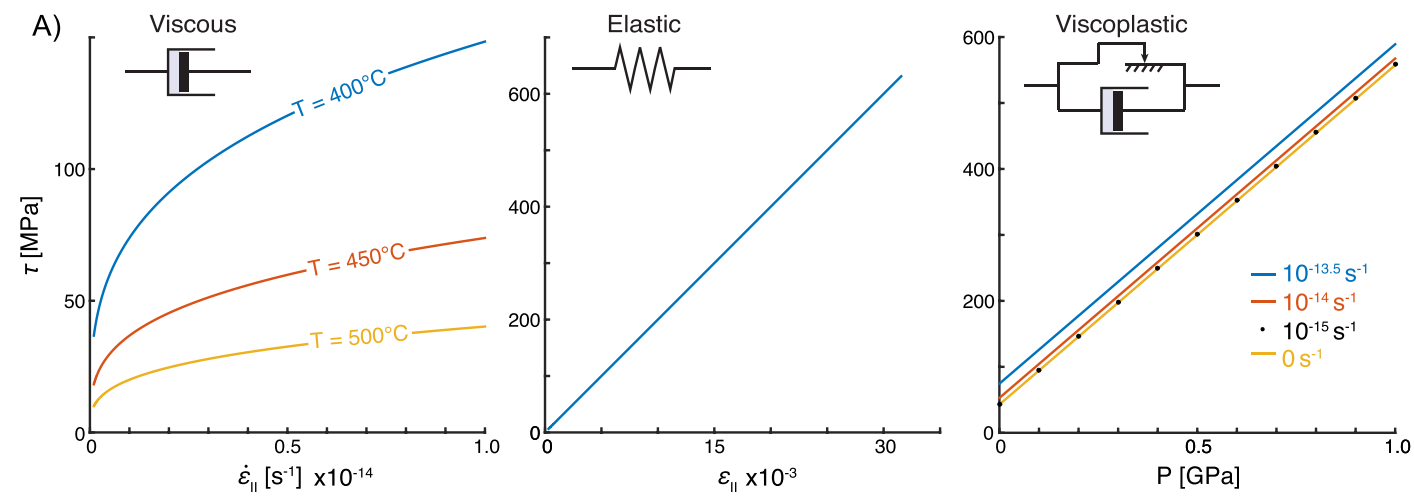

B)

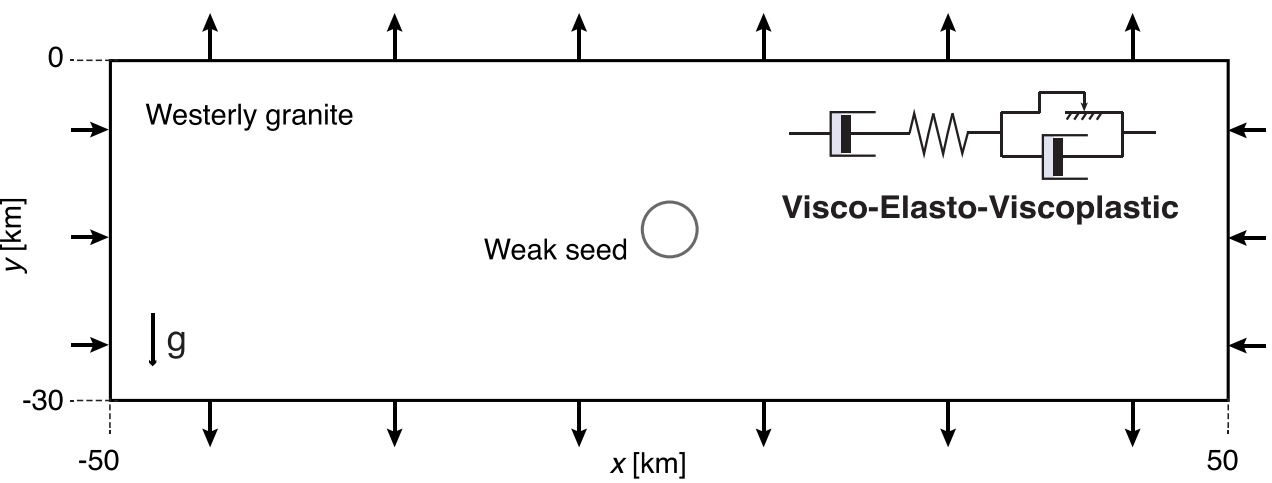

Figure 1. (a) Rheological elements in the visco-elasto-viscoplastic model (V-E-VP). From left to right: temperature and strain-rate dependent viscous creep, linear elasticity and pressure, and strain-rate-dependent viscoplastic flow.

(b) Model configuration and boundary conditions for the compression case. $g$ represents the acceleration of gravity.

We solve the balance of momentum together with the constitutive model that describes the V-E-VP rheology using a finite difference scheme. The code is based on the M2Di routines (Räss et al., 2017), which allow for solving the resulting set of nonlinear algebraic equations using global Newton-Raphson iterations. At the grid level (vertices and centroids), the nonlinear rheological equation, equation (1), is solved at each global iteration using local Newton-Raphson iterations (Popov \& Sobolev, 2008; Schmalholz \& Duretz, 2017). The related scripts are made publicly available as part of the M2Di routines.

The model consists of a $100 \times 30 \mathrm{~km}$ slice of Westerly Granite (Hansen \& Carter, 1983), which comprises an imperfection at the center of the domain. This weak inclusion with a $2 \mathrm{~km}$ radius serves to initiate localized deformations. The model configuration is thus perfectly symmetric. The model includes a vertical temperature gradient $\left(-15^{\circ} \mathrm{C} \mathrm{km}^{-1}\right)$, a constant density $\left(2,700 \mathrm{~kg} \mathrm{~m}^{-3}\right)$, and the acceleration of gravity $\left(g_{y}=-10 \mathrm{~m} \mathrm{~s}^{-2}\right)$. The domain is subjected to kinematic boundary conditions, which cause a pure shear stress state (Figure 1B). All boundaries are free to slip. The material can behave in a ductile manner in the lower, hot part of the domain (displaying temperature-dependent power law creep), and in an elasto-viscoplastic manner in the upper, cold part of the domain. The parameters are given in Table 1 and in the caption of Figure 1. We note that the V-E-VP rheology requires an additional viscosity parameter, $\eta^{\mathrm{vp}}$. We have chosen this viscosity based on the magnitude of the boundary strain rate $\dot{\varepsilon}_{\mathrm{BC}}$, which was set to $10^{-15} \mathrm{~s}^{-1}$. We have assumed that, in the basic pure shear state of deformation, the additional stress, or overstress $\hat{\sigma}$, caused by the damper parallel to the plastic slider, should be in the order of $1 \mathrm{MPa}$. The resulting viscosity $\eta^{\mathrm{vp}}=\hat{\sigma} / \dot{\varepsilon}_{\mathrm{BC}}=10^{21} \mathrm{~Pa} \cdot \mathrm{s}$.

Table 1

Rheological Parameters Used in the Simulations

\begin{tabular}{cccccccc}
\hline & $A\left[\mathrm{~Pa}^{-n} \mathrm{~s}^{-1}\right]$ & $Q\left[\mathrm{~J} \mathrm{~mol}^{-1}\right]$ & $n$ & $G[\mathrm{~Pa}]$ & $C[\mathrm{~Pa}]$ & $\phi$ & $\eta^{\mathrm{vp}}[\mathrm{Pa} \mathrm{s}]$ \\
\hline Crust & $3.1623 \times 10^{-26}$ & $186.5 \times 10^{3}$ & 3.3 & $10^{10}$ & $5.0 \times 10^{7}$ & $\arctan (0.6)$ & $10^{21}$ \\
Imperfection & $1.0 \times 10^{-20}$ & 0 & 1.0 & $10^{10}$ & $10^{5}$ & 0.0 & $10^{21}$ \\
\hline
\end{tabular}



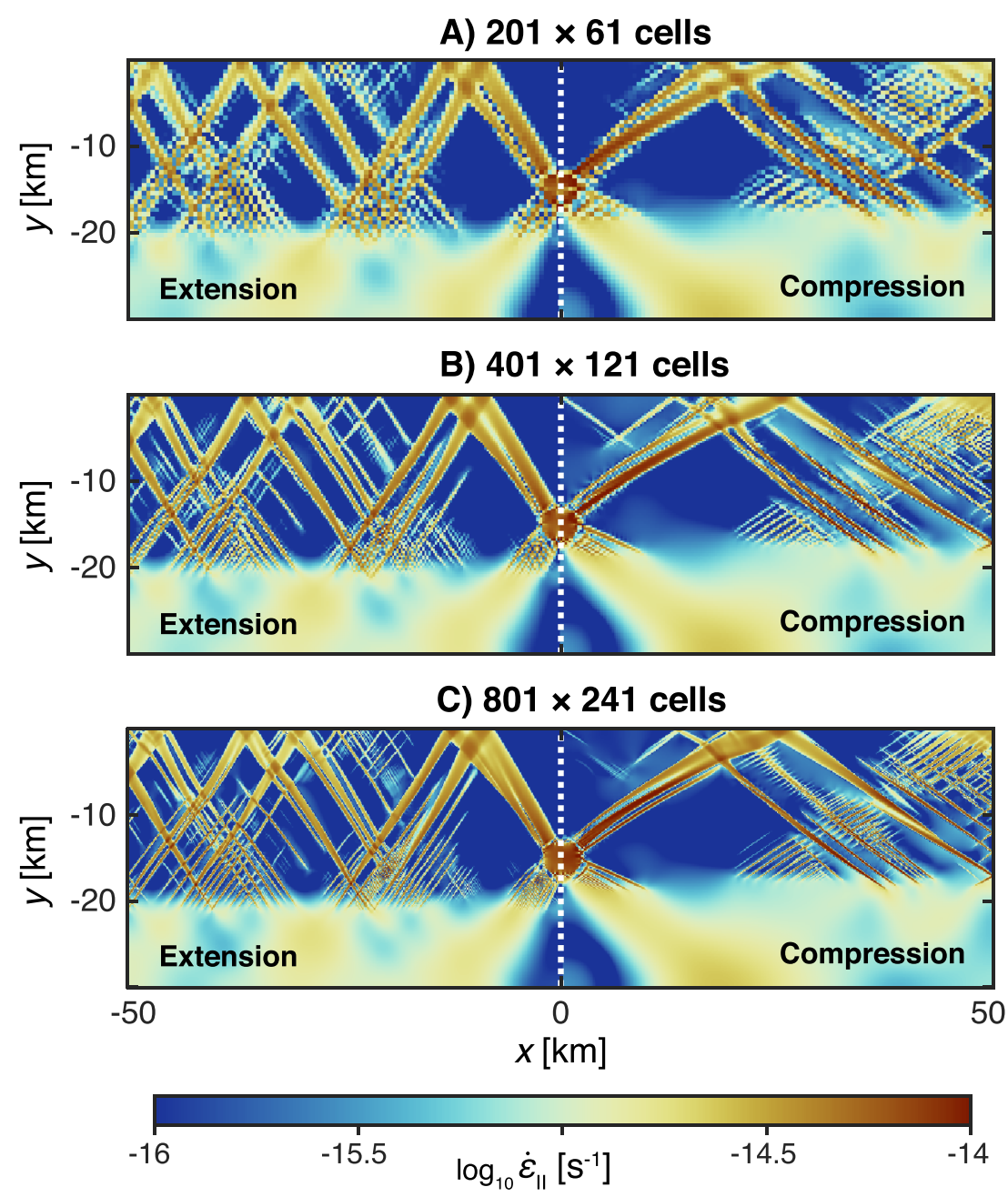

Figure 2. Simulations for various resolutions under extension (left-hand side) and compression (right-hand side). The colors correspond to the magnitude of the deviatoric strain rate $\left(\dot{\varepsilon}_{\mathrm{II}}\right)$. Panels (a), (b), and (c) corresponds to increasing grid resolutions. The surface temperature was set equal to $20^{\circ} \mathrm{C}$, the temperature gradient was $15^{\circ} \mathrm{C} \mathrm{km}^{-1}$, and the background strain rate was $10^{-15} \mathrm{~s}^{-1}$.

\section{Results}

The model undergoes compression or extension during $\approx 1.3 \mathrm{My}$ (101 time steps of $4 \times 10^{11} \mathrm{~s}$ ). During this time, the stress field can fully build up. With ongoing tectonic straining, shear bands emerge in the elasto-viscoplastic parts of the crust. They generally initiate from the top surface where the yield stress is minimal $(\approx C)$, propagate downward, and finally merge with deeper branches generated around the imperfection. Shear bands reflect at the brittle-ductile transition and at the top surface, resulting in an anastomosed shear band pattern (Figure 2). Detailed evolution is depicted in Figure S1.

We first emphasize that, different from models based on a visco-plastic (V-P) or visco-elastic-plastic (V-E-P) rheology, the V-E-VP model is normally able to satisfy a tight tolerance for the momentum balance within a reasonable number of iterations. Figure 3 shows that, when using the V-E-VP rheology, 10 Newton-Raphson iterations or less within a time step are normally sufficient to converge toward an equilibrium state. Moreover, this number is almost independent of the numerical resolutions. This is in contrast with models using a V-E-P rheology, which always require more than 10 iterations at each time step and often do not reach convergence. While algorithms based on time step reduction (e.g., Popov \& Sobolev, 2008) or line searches (e.g., Duretz, Souche, et al., 2018) may help, they do not ensure convergence. Moreover, with a V-E-P rheology 


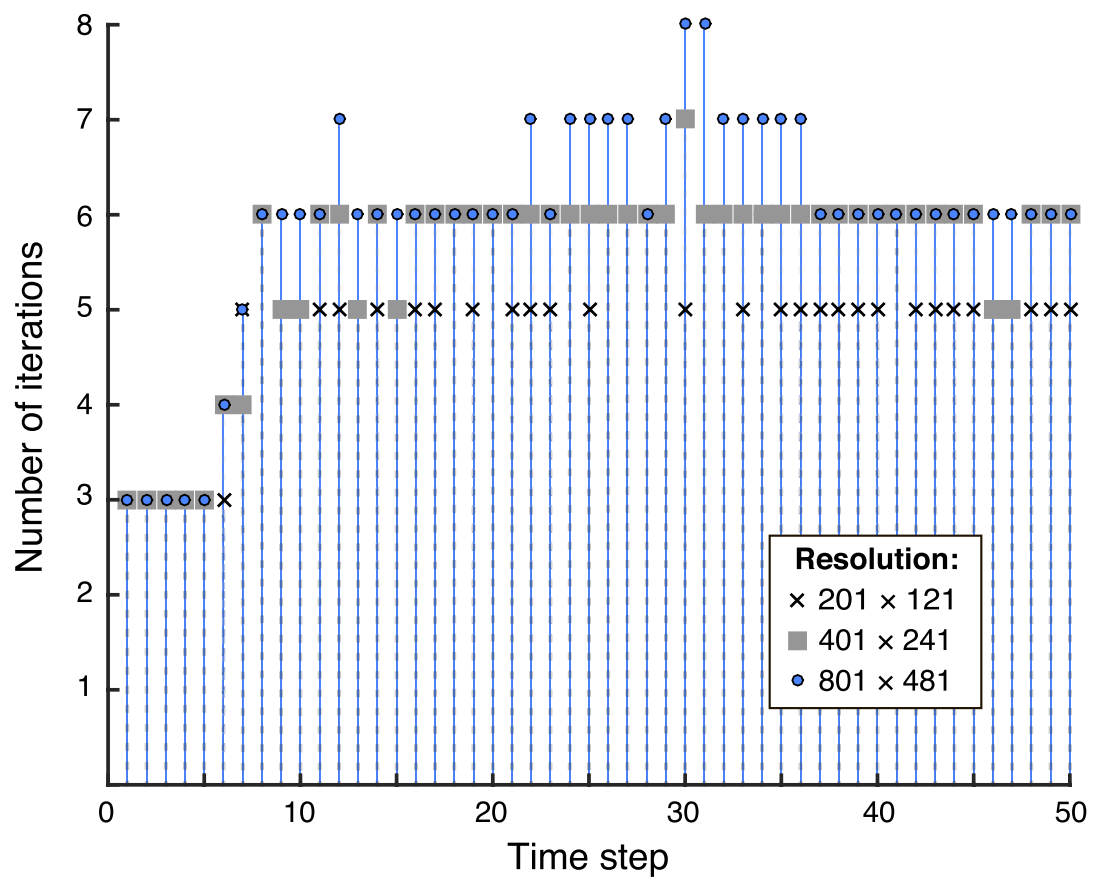

Figure 3. Global nonlinear convergence of V-E-VP models depicted in Figure 2 (compression). V-E-P models are not depicted as they always require more than 10 iterations and usually do not globally converge.

convergence problems worsen with grid refinement (e.g., Duretz, Souche, et al., 2018), while the convergence characteristics (e.g., the number of iterations needed to obtain a convergence solution) are almost independent of the discretisation for a V-E-VP rheology (Figure 3).

We next analyze the shear band pattern at the end of the simulations for different resolutions (Figure 2). The first observation is that shear band angles are not affected by the use of a V-E-VP rheology. Most shear bands initiate at angles between $55^{\circ}$ and $60^{\circ}$ in extension, and between $30^{\circ}$ and $35^{\circ}$ in compression. The overall shear band pattern is remarkably stable upon increasing the spatial (Figure 2) or temporal resolution (Figure S2). However, an increased spatial resolution reveals the occurrence of second-order, finer structures. Hence, full convergence (in the sense that all secondary structures are resolved) cannot yet be ascertained at the current level of discretization.

It is however clear that shear banding patterns converge with increasing resolution in V-E-VP models. Figure 4 depicts horizontal profiles of the invariant of deviatoric strain rate sampled at depth of $-10 \mathrm{~km}$. For both V-E-VP and V-E-P models, we have computed the correlation coefficient between the highest resolution $(1,101 \times 661$ cells) and lower resolution models. For the V-E-VP model (Figure 4a), strain rate profiles comprise in phase shear bands, with a correlation coefficient varying from 0.5 to 0.85 from low to high resolution. In particular, we see the emergence of thick shear bands in the middle of the domains, whose widths are independent from the grid spacing. In contrast, V-E-P models are characterized by out of phase shear bands, with correlation coefficients ranging between -0.03 and 0.02 and no notable improvement upon mesh refinement (Figure S3).

It is also important to point out that the deformation patterns are perfectly symmetric (Figure 4a), which is a consequence of the fact that, when using the V-E-VP model, momentum balance can be satisfied within a tight tolerance $\left(5 \times 10^{-10}\right.$ for both relative and absolute momentum residuals in $\mathrm{L}_{2}$ norm). Again, this is in contrast to the results for the V-E-P rheology, which fails to produce a strictly symmetric deformation pattern (Figure 4b), even though the applied initial and boundary conditions are perfectly symmetric and are therefore not reliable. We recognize that it is not impossible that symmetric solutions are obtained for V-E-P rheologies. Indeed, imperfections are responsible for triggering symmetry-breaking solutions, and even round-off errors can act as imperfections, depending on the particular algorithm and even implementation. We wish to emphasize, however, that in such cases, the algorithm essentially fails to pick up the more critical, symmetry-breaking solution. 
A)

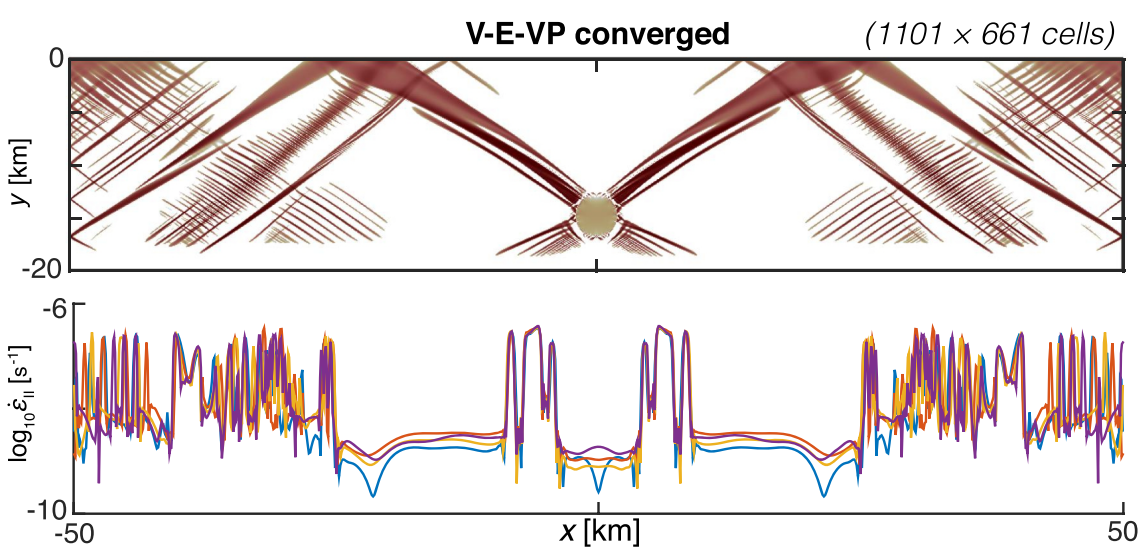

B)
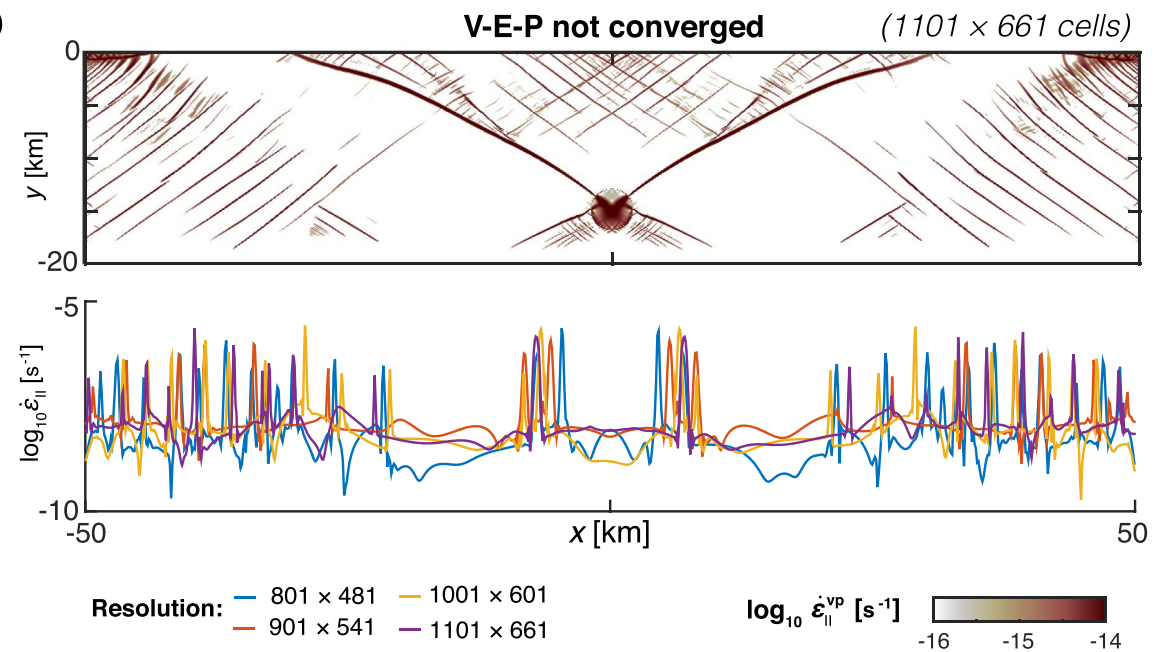

Figure 4. Colormaps of the second invariant of the plastic strain rate tensor (enlarged) and horizontal profiles of the second invariant of the total strain rate for V-E-VP and V-E-P models. Profiles were probed at $y=-10 \mathrm{~km}$ in models of various grid resolutions (see legend). (a) V-E-VP models exhibit symmetric shear banding and correlating shear band locations at different mesh resolutions. (b) V-E-P models show erratic shear band locations at different resolutions as well as loss of symmetry.

The additional damper in the V-E-VP model causes an overstress, that is, a stress in addition to the plastic slider. To assess the relevance of the V-E-VP model for modeling frictional lithospheric deformations, we have compared our predicted stress states with laboratory data of rock friction (Figure 5a). For normal stresses in excess of $200 \mathrm{MPa}$, a reasonable agreement was found between experimentally obtained and numerically calculated stresses. For normal stresses below $200 \mathrm{MPa}$ a deviation was observed, since our model only features a single yield envelope with a nonzero cohesion (Table 1). We have also verified that the model satisfies fundamental relations, which characterize the frictional domain, and assumes a rate-independent plastic rheology. We report profiles of shear stress as a function of depth for extension as well as compression (Figure 5b). As expected for a frictional layer with a friction angle of $30^{\circ}$, the shear stress is proportional to one third of the lithostatic pressure in extension and to the lithostatic pressure under compression. We also report profiles of the pressure with increasing depth in extension and compression (Figure 5c). The pressure in the frictional layer is proportional to two thirds of the lithostatic pressure in extension and two times the lithostatic pressure in compression. The V-E-VP model is thus in agreement with analytical predictions (Petrini \& Podladchikov, 2000), and the overstress inherent in the V-E-VP formulation does not result in a significant deviation from laboratory data, while still satisfying fundamental relations for frictional deformation. 

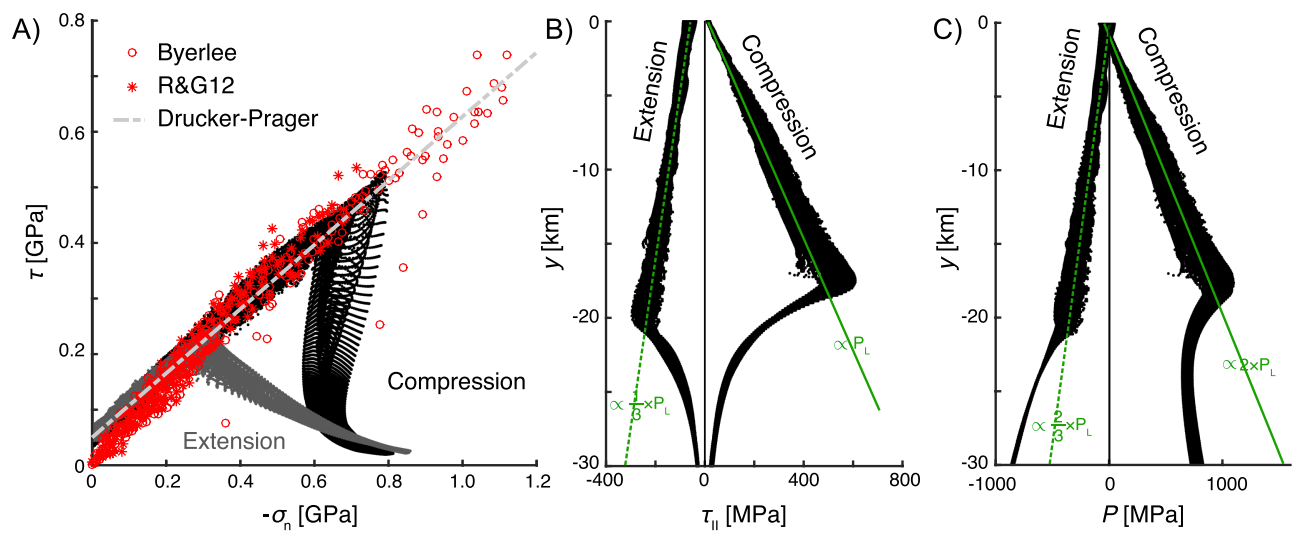

Figure 5. Verification and validation of the V-E-VP model. Panel (a) shows the comparison of stress states extracted from the simulations (black and gray dots) with laboratory data of Byerlee (1978) and Rutter and Glover (2012). The gray dashed line corresponds the rate-independent Drucker-Prager yield envelope. Panel (b) corresponds to vertical profiles of the magnitude of the deviatoric stress $\tau_{\mathrm{II}}$. Green lines correspond to analytical predictions of the evolution of the deviatoric stresses with depth using a rate-independent Drucker-Prager model. Panel (c) corresponds to the vertical pressure profiles. Green lines are analytically predicted pressure-depth profiles of Petrini and Podladchikov (2000).

\section{Summary and Discussion}

The V-E-VP rheology is a potential cure for the lack of convergence and the pathological mesh dependence of geodynamic models, which involve localized frictional deformations. These issues are particularly relevant for rheological models, which feature strain softening and/or nonassociated plastic flow but lack an internal length scale. Physically meaningful length scales may be introduced by accounting for more complex multiphysics processes such as thermo-mechanical (Duretz et al., 2015) or hydro-mechanical couplings (Brantut et al., 2017). Other, purely mechanically motivated regularization mechanisms have been proposed mainly in the engineering literature, including nonlocal plasticity (Baźant \& Jirasek, 2002), gradient plasticity (de Borst \& Mühlhaus, 1992), and the Cosserat continuum (de Borst, 1991; Mühlhaus \& Vardoulakis, 1987). The viscoplastic approach is the simplest way of regularization, as it does not increase the cost of the computations (i.e., not increasing the number of degrees of freedom), nor does it alter the structure of existing geodynamic codes. Moreover, the approach is also applicable to models that include plastic volumetric deformations (Duretz et al., 2019; Jacquey \& Cacace, 2020a) and can be extended to constitutive models involving damage laws (Jacquey \& Cacace, 2020b), grain-size evolution, or rate and state friction laws.

Another aspect that should be highlighted is the role of elasticity. By including elasticity, it is possible to resolve progressive stress build up during simulations, the initiation and propagation of shear bands, and elasto-(visco)plastic loading and unloading near shear bands. The inclusion of elasticity in the rheological model is crucial for establishing robust numerical models that result in correct shear band patterns and in a smooth convergence toward a momentum balance within a tight tolerance. Neglecting this stress buildup enforces the construction of complex shear band networks within a single time step, which can lead to an erratic non-linear process (Spiegelman et al., 2016).

Progressive loss of symmetry, in spite of the initial conditions, boundary conditions, and all other features being symmetric, is often observed in numerical models of tectonic deformation (e.g., Buiter et al., 2006). Such loss of symmetry was attributed to strain softening (Huismans \& Beaumont, 2003) and subsequent mode selection (Huismans et al., 2005). Indeed, the introduction of strain softening, or nonassociated plasticity as in this paper, can lead to loss of uniqueness of the boundary value problem. For nonregularized rheologies, like the V-P or V-E-P models, the number of solutions can even be infinite and is in practice set by the discretization. This is the underlying reason that the asymmetry tends to worsen upon grid refinement. Moreover, imperfections are needed to trigger symmetry-breaking solutions, and since even round-off errors can act as imperfections, an inability to obtain an equilibrium solution, as is frequently observed in codes exploiting V-P or V-E-P models, will contribute to the chance that asymmetric solutions are obtained, which are not triggered by a physical imperfection. Therefore, care has to be taken when interpreting results of models involving faulting since important features may result from numerical inaccuracies. The use of V-E-VP 
model, which delivers converged numerical solutions and reduces mesh sensitivity, will likely improve this aspect.

More generally, we expect that the use of V-E-VP models will markedly reduce the variability of results that so far prevails in the modeling of brittle tectonic processes (Buiter et al., 2006, 2016). Further work is needed involving for instance other discretization methods such as finite elements, in order to evaluate the robustness of V-E-VP models and to determine wether the V-E-VP approach is the most adequate regularization method for the purpose of geodynamic modeling.

Here we have considered a linear viscous viscoplastic element, which may result in large overstress in regions where the viscoplastic strain rate is large. The impact of a power law viscoplastic elements, resulting in smaller overstress, will need to be investigated. Models would benefit from higher-order time integration (e.g., Duretz, Räss, et al., 2018) and adaptative time integration, which should further increase their robustness. Future work should also address the use of more sophisticated plasticity models, such as multisurface plasticity or nonlinear envelopes. Inclusion of the latter features will be essential for accurately resolving key processes (e.g., compaction/dilation bands and dyking) that will arise as the resolution power and the physics (e.g., multiphase flow and magmatic processes) of geodynamic models are continuously enriched.

\section{Acknowledgments}

The authors wish to thank Boris Kaus and Cédric Thieulot for their reviews as well as the editor Jeroen Ritsema for handling the manuscript. The authors acknowledge the French program NEEDS for its financial support to the project. The research reported in this article has been partially supported by the European Research Council under Grant 664734 "PoroFrac." This study is based on forward numerical simulations and does not involve any new data. The simulations can be reproduced using the open source routines M2Di_VEVP (https://bitbucket.org/lraess/m2di/src/ master/M2Di2_VEVP_ CrustalShearBanding/)

\section{References}

Adamuszek, M., Dabrowski, M., \& Schmid, D. W. (2016). Folder: A numerical tool to simulate the development of structures in layered media. Journal of Structural Geology, 84, 85-101. https://doi.org/10.1016/j.jsg.2016.01.001

Anderson, E. M. (1905). The dynamics of faulting. Transactions of the Edinburgh Geological Society, 8(3), 387-402. https://doi.org/10.1144/ transed.8.3.387

Anderson, E. M. (1951). The dynamics of faulting and dyke formation: With applications to Britain (2nd ed.). Edinburgh and London: Oliver and Boyd.

Arthur, J. R. F., Dunstan, T., Al-Ani, Q. A. J. L., \& Assadi, A. (1977). Plastic deformation and failure in granular media. Géotechnique, 27(1), 53-74.

Baźant, Z. P., \& Jirasek, M. (2002). Nonlocal integral formulations of plasticity and damage: Survey of progress. Journal of Engineering Mechanics, 128(11), 1119-1149.

Bercovici, D., Ricard, Y., \& Schubert, G. (2001). A two-phase model for compaction and damage: 1. General theory. Journal of Geophysical Research, 106(B5), 8887-8906.

Brantut, N., Stefanou, I., \& Sulem, J. (2017). Dehydration-induced instabilities at intermediate depths in subduction zones. Journal of Geophysical Research: Solid Earth, 122, 6087-6107. https://doi.org/10.1002/2017JB014357

Brun, J., Gutscher, M. A., \& dekorp-ecors teams (1992). Deep crustal structure of the rhine graben from DEKORP-ECORS seismic reflection data: A summary. Tectonophysics, 208(1), 139-147. https://doi.org/10.1016/0040-1951(92)90340-Cgeodynamics of rifting, volume 1 Case history studies on rifts: Europe and Asia.

Buiter, S. J. H., Babeyko, A. Y., Ellis, S., Gerya, T. V., Kaus, B. J. P., Kellner, A., et al. (2006). The numerical sandbox: Comparison of model results for a shortening and an extension experiment. Geological Society, London Special Publications, 253(1), 29-64.

Buiter, S. J., Schreurs, G., Albertz, M., Gerya, T. V., Kaus, B., Landry, W., et al. (2016). Benchmarking numerical models of brittle thrust wedges. Journal of Structural Geology, 92, 140-177. https://doi.org/10.1016/j.jsg.2016.03.003

Byerlee, J. (1978). Friction of rocks. Pure and Applied Geophysics, 116, 615-626.

Coward, M. P., Gillcrist, R., \& Trudgill, B. (1991). Extensional structures and their tectonic inversion in the western alps. Geological Society, London Special Publications, 56(1), 93-112. https://doi.org/10.1144/GSL.SP.1991.056.01.07

de Borst, R. (1991). Simulation of strain localization: A reappraisal of the Cosserat continuum. Engineering Computations, 8, 317-332.

de Borst, R., \& Duretz, T. (2020). On viscoplastic regularisation of strain-softening rocks and soils. International Journal for Numerical and Analytical Methods in Geomechanics. https://doi.org/10.1002/nag.3046

de Borst, R., \& Mühlhaus, H. B. (1992). International Journal for Numerical Methods in Engineering, 35, 521-539.

de Borst, R., Sluys, L. J., Mühlhaus, H. B., \& Pamin, J. (1993). Fundamental issues in finite element analysis of localization of deformation. Engineering Computations, 10(2), 99-122.

Duretz, T., de Borst, R., \& Le Pourhiet, L. (2019). On finite thickness of shear bands in frictional viscoplasticity, and implications for lithosphere dynamics. Geochemistry Geophysics Geosystems, 20, 5598-5616. https://doi.org/10.1029/2019GC008531

Duretz, T., Räss, L., Podladchikov, Y., \& Schmalholz, S. (2018). Resolving thermomechanical coupling in two and three dimensions: Spontaneous strain localization owing to shear heating. Geophysical Journal International, 216(1), 365-379. https://doi.org/10.1093/gji/ ggy 434

Duretz, T., Schmalholz, S. M., \& Podladchikov, Y. Y. (2015). Shear heating-induced strain localization across the scales. Philosophical Magazine, 95(28-30), 3192-3207.

Duretz, T., Souche, A., de Borst, R., \& Le Pourhiet, L. (2018). The benefits of using a consistent tangent operator for viscoelastoplastic computations in geodynamics. Geochemistry, Geophysics, Geosystems, 19, 4904-4024. https://doi.org/10.1029/2018GC007877

Fraters, M. R. T., Bangerth, W., Thieulot, C., Glerum, A. C., \& Spakman, W. (2019). Efficient and practical Newton solvers for non-linear Stokes systems in geodynamic problems. Geophysical Journal International, 218(2), 873-894. https://doi.org/10.1093/gii/ggz183

Fullsack, P. (1995). An arbitrary Lagrangian-Eulerian formulation for creeping flows and its application in tectonic models. Geophysical Journal International, 120(1), 1-23.

Gerbault, M., Poliakov, A. N. B., \& Daignieres, M. (1998). Prediction of faulting from the theories of elasticity and plasticity: What are the limits? Journal of Structural Geology, 20(2), 301-320.

Hansen, F. D., \& Carter, N. L. (1983). In A. College Station (Ed.), Semibrittle creep of dry and wet westerly granite at 1000 mpa, in Presented at the The 24th U.S. Symposium on Rock Mechanics (USRMS) (pp. 20). Texas. https://doi.org/ARMA-83-0429

Heeres, O. M., Suiker, A. S. J., \& de Borst, R. (2002). A comparison between the Perzyna viscoplastic model and the consistency viscoplastic model. European Journal of Mechanics: A/Solids, 21, 1-12. 
Hubbert, M. K. (1937). Theory of scale models as applied to the study of geologic structures. GSA Bulletin, 48(10), 1459-1520. https://doi. org/10.1130/GSAB-48-1459

Huismans, R. S., \& Beaumont, C. (2003). Symmetric and asymmetric lithospheric extension: Relative effects of frictional-plastic and viscous strain softening. Journal of Geophysical Research, 108(B10), 2496. https://doi.org/10.1029/2002JB002026

Huismans, R. S., Buiter, S. J. H., \& Beaumont, C. (2005). Effect of plastic-viscous layering and strain softening on mode selection during lithospheric extension. Journal of Geophysical Research, 110, B02406. https://doi.org/10.1029/2004JB003114

Jacquey, A. B., \& Cacace, M. (2020a). Multiphysics modeling of a brittle-ductile lithosphere: 1. Explicit visco-elasto-plastic formulation and its numerical implementation. Journal of Geophysical Research: Solid Earth, 125, e2019JB018474. https://doi.org/10.1029/2019JB018474

Jacquey, A. B., \& Cacace, M. (2020b). Multiphysics modeling of a brittle-ductile lithosphere: 2. Semi-brittle, semi-ductile deformation and damage rheology. Journal of Geophysical Research: Solid Earth, 125, e2019JB018475. https://doi.org/10.1029/2019JB018475

Kaus, B. J. P. (2010). Factors that control the angle of shear bands in geodynamic numerical models of brittle deformation. Tectonophysics, 484, 36-47.

Kiss, D., Podladchikov, Y., Duretz, T., \& Schmalholz, S. M. (2019). Spontaneous generation of ductile shear zones by thermal softening: Localization criterion, 1D to 3D modelling and application to the lithosphere. Earth and Planetary Science Letters, 519, 284-296. https:// doi.org/10.1016/j.epsl.2019.05.026

Lemiale, V., Mühlhaus, H. B., Moresi, L., \& Stafford, J. (2008). Shear banding analysis of plastic models formulated for incompressible viscous flows. Physics of the Earth and Planetary Interiors, 171, 177-186.

McClay, K. (1990). Extensional fault systems in sedimentary basins: A review of analogue model studies. Marine and Petroleum Geology, 7(3), 206-233. https://doi.org/10.1016/0264-8172(90)90001-W

McLeod, A. E., Dawers, N. H., \& Underhill, J. R. (2000). The propagation and linkage of normal faults: Insights from the Strathspey - Brent - Statfjord fault array, northern North Sea. Basin Research, 12(3-4), 263-284. https://doi.org/10.1111/j.1365-2117.2000.00124.x

Moresi, L., Dufour, F., \& Mühlhaus, H.-B. (2003). A lagrangian integration point finite element method for large deformation modeling of viscoelastic geomaterials. Journal of Computational Physics, 184(2), 476-497. https://doi.org/10.1016/S0021-9991(02)00031-1

Moresi, L., Mühlhaus, H. B., Lemiale, V., \& May, D. A. (2007). Incompressible viscous formulations for deformation and yielding of the lithosphere, Geological Society London. Special Publications, 282, 457-472.

Mühlhaus, H. B., \& Vardoulakis, I. (1987). The thickness of shear bands in granular materials. Géotechnique, 37, 271-283.

Ori, G. (1989). Geologic history of the extensional basin of the Gulf of Corinth (Miocene-Pleistocene) Greece. Geology, 17(10), 918-921.

Petrini, K., \& Podladchikov, Y. (2000). Lithospheric pressure-depth relationship in compressive regions of thickened crust. Journal of Metamorphic Geology, 18(1), 67-77. https://doi.org/10.1046/j.1525-1314.2000.00240.x

Poliakov, A., Podladchikov, Y., \& Talbot, C. (1993). Initiation of salt diapirs with frictional overburdens: Numerical experiments. Tectonophysics, 228((3)), 199-210.

Popov, A. A., \& Sobolev, S. V. (2008). SLIM 3D: A tool for three-dimensional thermomechanical modeling of lithospheric deformation with elasto-visco-plastic rheology. Physics of the Earth and Planetary Interiors, 171, 55-75.

Räss, L., Duretz, T., Podladchikov, Y. Y., \& Schmalholz, S. M. (2017). M2Di: Concise and efficient MATLAB 2-D Stokes solvers using the Finite Difference Method. Geochemistry Geophysics Geosystems, 18, 755-768. https://doi.org/10.1002/2016GC006727

Rutter, E. H., \& Glover, C. T. (2012). The deformation of porous sandstones; are Byerlee friction and the critical state line equivalent? Journal of Structural Geology, 44, 129-140. https://doi.org/10.1016/j.jsg.2012.08.014

Schmalholz, S. M., \& Duretz, T. (2017). Impact of grain size evolution on necking in calcite layers deforming by combined diffusion and dislocation creep. Journal of Structural Geology, 103, 37-56. https://doi.org/10.1016/j.jsg.2017.08.007

Spiegelman, M., May, D. A., \& Wilson, C. R. (2016). On the solvability of incompressible Stokes with viscoplastic rheologies in geodynamics. Geochemistry, Geophysics Geosystems, 17, 2213-2238. https://doi.org/10.1002/2015GC006228

Tackley, P. J. (2000). Self-consistent generation of tectonic plates in time-dependent, three-dimensional mantle convection simulations 2. strain weakening and asthenosphere. Geochemistry Geophysics Geosystems, 1, 1026.

Ulvrova, M. M., Coltice, N., Williams, S., \& Tackley, P. J. (2019). Where does subduction initiate and cease? a global scale perspective. Earth and Planetary Science Letters, 528, 115-836. https://doi.org/10.1016/j.epsl.2019.115836

Vermeer, P. A. (1990). The orientation of shear bands in biaxial tests. Géotechnique, 40(2), 223-236. https://doi.org/10.1680/geot.1990.40. 2.223

Vermeer, P. A., \& de Borst, R. (1984). Non-associated plasticity for soils, concrete and rock. Heron, 29(3), 3-64.

Wang, W. M., Sluys, L. J., \& de Borst, R. (1997). Viscoplasticity for instabilities due to strain softening and strain-rate softening. International Journal for Numerical Methods in Engineering, 40(20), 3839-3864.

Willett, S. D. (1992). In K. R. McClay (Ed.), Dynamic and kinematic growth and change of a Coulomb wedge in Thrust Tectonics (pp. 19-31). Dordrecht: Springer. 